Supporting Information

\title{
Monodispersed Spherical Colloids of Se@CdSe: Synthesis and Their Use as Building Blocks in Fabricating Photonic Crystals
}

\author{
Unyong Jeong, Jong-Uk Kim and Younan Xia* \\ Department of Chemistry, University of Washington, Seattle, Washington 98195 \\ E-mail: xia@chem.washington.edu
}

Zhi-Yuan Li

Institute of Physics, Chinese Academy of Sciences, Beijing 10080, P. R. China 


\section{Experimental}

Chemicals and Materials. Selenious acid $\left(\mathrm{H}_{2} \mathrm{SeO}_{3}, 99.99 \%\right)$, hydrazine hydrate $\left(\mathrm{N}_{2} \mathrm{H}_{4} \cdot \mathrm{H}_{2} \mathrm{O}\right.$, 55\%), poly(vinyl pyrrolidone) (PVP, $\left.\mathrm{M}_{\mathrm{w}}=55,000\right)$, silver nitrate $\left(\mathrm{AgNO}_{3}, 99.9 \%\right)$, cadmium nitrate tetrahydrate $\left(\mathrm{Cd}\left(\mathrm{NO}_{3}\right)_{2} \cdot 4 \mathrm{H}_{2} \mathrm{O}, 98 \%\right.$, tributylphosphine $\left(\mathrm{C}_{12} \mathrm{H}_{27} \mathrm{P}\right.$ or $\left.\mathrm{TBP}, 97 \%\right)$ were purchased from Aldrich. Ethylene glycol $\left(\mathrm{HOCH}_{2} \mathrm{CH}_{2} \mathrm{OH}, \mathrm{EG}, 99.9 \%\right)$ and methanol (99.8\%) were obtained from Fluka and EMD, respectively. All chemicals were used as received without further purification.

Synthesis of Monodispersed a-Se Spherical Colloids. $0.87 \mathrm{~mL}$ of hydrzine hydrate was added to $200 \mathrm{~mL}$ pure EG hosted in a 500-mL round bottom flask. The temperature was maintained at $15{ }^{\circ} \mathrm{C}$ using cold water bath. After mixing for 10 min under magnetic stirring, 40 $\mathrm{mL}$ of selenious acid $(0.07 \mathrm{M}$, pre-dissolved in EG) was introduced and the reaction was allowed to proceed for $2 \mathrm{~h}$.

Synthesis of Se@Ag $\mathrm{Ag}_{2} \mathrm{Se}$ Core-Shell Spherical Colloids. Since the residual hydrazine in the suspension of $a$-Se colloids is also able to quickly reduce $\mathrm{AgNO}_{3}$ to form $\mathrm{Ag}$ nanoparticles and agglomerates, all remaining hydrazine has to be removed via vacuum distillation before $\mathrm{AgNO}_{3}$ is introduced into the system. To form $\mathrm{Se} @ \mathrm{Ag}_{2} \mathrm{Se}$ colloids, PVP solution ( $1 \mathrm{~g}$ in $100 \mathrm{~mL}$ EG) was added to the $a$-Se colloids suspended in EG. $\mathrm{AgNO}_{3}$ solution $(0.2 \mathrm{~g}$ in $0.2 \mathrm{~mL}$ of pure water) was then added dropwise and the solution immediately changed the color from light red to dark brown. After the reaction had proceeded for $2 \mathrm{~h}, 200 \mathrm{~mL}$ water was added to the mixture and the core-shell colloids were centrifuged. To remove excess EG and PVP in the suspension, dispersion and centrifuge was repeated four times with pure water and the product was finally dried in air. The thickness of $\mathrm{Ag}_{2}$ Se shells could be controlled by adjusting the molar ratio of $\mathrm{AgNO}_{3}$ to $a$-Se. ${ }^{8} \quad$ In general, more than $1 \mathrm{~g}$ of $\mathrm{AgNO}_{3}$ is needed for a complete conversion of $a$ Se cores into $\mathrm{Ag}_{2} \mathrm{Se}$ colloids. 
Conversion of Se@Ag $g_{2}$ Se to Se@CdSe Core-Shell Colloids. The Se@ $\mathrm{Ag}_{2} \mathrm{Se}$ colloids (0.5 g) produced above were re-dispersed in $100 \mathrm{~mL}$ of methanol and $20 \mathrm{~mL}$ of it was placed in a 50$\mathrm{mL}$ round bottom flask. $\quad 0.1 \mathrm{~g}$ PVP and excessive cadmium nitrate tetrahydrate solution $(1 \mathrm{~g})$ were then introduced. After the temperature was raised to $50{ }^{\circ} \mathrm{C}$ in an oil bath, tributylphosphine $(20 \mu \mathrm{L}, 0.1 \%$ solution in methanol) was introduced. The reaction mixture turned into light brown within $30 \mathrm{~min}$. For the kinetic study, $3 \mathrm{~mL}$ of the solution was taken from the reaction mixture and quickly centrifuged and washed four times with methanol. The reaction was completed at $150 \mathrm{~min}$. To check the dependence of reaction rate on the amount of TBP, $1 \%$ of TBP was introduced and the reaction was allowed to proceed under the same condition for $6 \mathrm{~h}$.

Conversion of Se@CdSe to Se@Ag Ag $_{2}$ Se Core-Shell Colloids. Se@CdSe colloids (0.05 g) were dispersed in methanol $(20 \mathrm{~mL})$ with the assistance of $0.1 \mathrm{~g}$ PVP. Upon addition of $0.5 \mathrm{~g}$ $\mathrm{AgNO}_{3}$ under magnetic stirring, the color immediately changed to dark brown and the conversion was completed within a few minutes. The colloids were washed and centrifuged with methanol more than four times and dried in air.

Removal of Un-reacted a-Se Cores. A small amount of the dried core-shell colloids was added to $1 \mathrm{~mL}$ hydrazine hydrate and sonicated. The color became red-brown within $5 \mathrm{~min}$, indicating removal of un-reacted $a$-Se cores from the core-shell colloids. After 30 min, the suspension was centrifuged and the solvent was decanted. To make sure that the $a$-Se cores had been completely removed, the same procedure was performed again and washed with pure water more than three times.

Instrumentation and Characterization. Scanning electron microscopy (SEM) images were captured using a field-emission microscope (Siron XL, FEI, Hillsboro, OR) operated at an acceleration voltage of $5 \mathrm{kV}$. The samples were directly imaged without coating their surfaces 
with conductive layers. Energy-dispersive X-ray spectroscopy (EDX, Genesis 2000, EDAX, Mahwah, NJ) was performed at an acceleration voltage of $15 \mathrm{kV}$. In order to improve the signal-to-noise ratio and thus obtain reliable data, we used a thick slab $(\sim 6 \mu \mathrm{m})$ of the colloid sample deposited on a silicon wafer, in combination with a beam spot of $>100 \mu \mathrm{m}^{2}$. Transmission electron microscopy (TEM) images were obtained using a Jeol JEM 1200 EX II microscope operated at $80 \mathrm{kV}$. One drop of water suspension of the colloidal sample was placed on the carbon-coated copper grid and the solvent was evaporated in a fume hood. X-ray diffraction (XRD) was performed on Philips PW-1710 diffractometer with a resolution of $0.02^{\circ}$ in $2 \theta$. The XRD sample was prepared by evaporating a highly concentrated colloid suspension in ethanol on a glass slide.

UV-visible Reflectance Spectra of the Photonic Crystals. Colloidal crystals were fabricated from Se@CdSe core-shell colloids with a total diameter of $214 \mathrm{~nm}$ and a shell thickness of $21 \mathrm{~nm}$ using a published procedure. The spectra were recorded using a fiber optic spectrometer (S2000, Ocean Optics, Dunedin, FL, USA). In the measurement, the incident light and detector were both oriented perpendicular to the (111) planes of the colloidal crystal. 


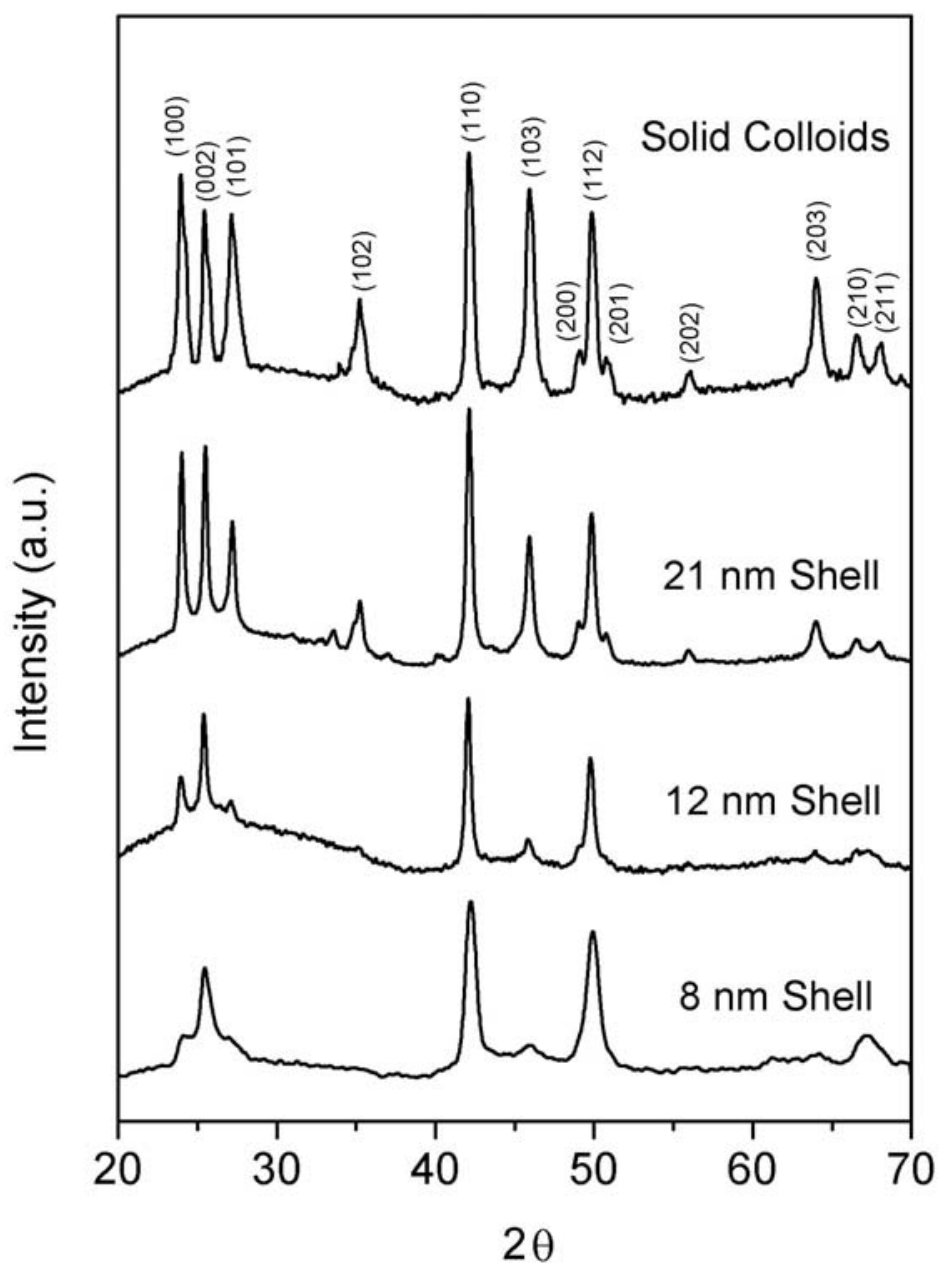

Figure S1. XRD patterns of Se@CdSe core-shells colloids with various shell thicknesses: 8, 12, and $21 \mathrm{~nm}$, together with solid CdSe colloids of $121 \mathrm{~nm}$ in radius. $\mathrm{Se} @ \mathrm{Ag}_{2} \mathrm{Se}$ core-shell colloids with different shell thickness and solid $\mathrm{Ag}_{2} \mathrm{Se}$ colloids were used as starting materials to prepare Se@CdSe. For colloids with 8-nm thick shells, the (002) peak of wurtzite lattice was predominent. As the thickness increased, the (100) peak grew and became comparable to the (002) peak when the shell was thinner. 



Figure S2. Dispersion curves of $a$-Se (A) and CdSe (B) used in the calculation of the reflectance spectrum of the photonic crystal in Figure 4. The dispersion curves, $\varepsilon(\lambda)=\varepsilon_{1}(\lambda)+i$ $\varepsilon_{2}(\lambda)$, were obtained from the refs. 19 and 20. 